\title{
Is this really a step forward?
}

\author{
Charles B. Huddleston, MD
}

From the Department of Surgery, St Louis University School of Medicine, St Louis, Mo.

Disclosures: Author has nothing to disclose with regard to commercial support.

Received for publication Aug 3, 2018; accepted for publication Aug 5, 2018; available ahead of print Sept 11, 2018.

Address for reprints: Charles B. Huddleston, MD, 1465 S. Grand Blvd, St Louis, MO 63104 (E-mail: Charles. huddleston@health.slu.edu).

J Thorac Cardiovasc Surg 2018;156:2035-6

$0022-5223 / \$ 36.00$

Copyright (C) 2018 by The American Association for Thoracic Surgery

https://doi.org/10.1016/j.jtcvs.2018.08.006

One of the issues of the Journal of Heart and Lung Transplantation that I look forward to reading is that containing the annual registry report detailing survival statistics for pediatric heart and lung transplantation over the 30 odd years that this subspecialty of cardiothoracic surgery has been practiced. The survival with pediatric lung transplantation was relatively poor in the "early era," with less than $50 \%$ of patients alive 5 years after the transplant procedure; likewise, the 5-year survival with pediatric heart transplantation in that era was $58 \%$. One would expect that with experience these figures would improve, and indeed pediatric heart transplant 5-year survival has gone from $58 \%$ to $83 \%$ in the most recent era. ${ }^{1}$ This represents a remarkable bit of progress at a time when the patients undergoing heart transplant as a group are generally more complex and sicker (higher percentage of status IA candidates, more patients being bridged with mechanical support) at the time of the transplant. ${ }^{2}$ In contrast, pediatric lung transplantation has shown rather meager improvement since its beginnings, going from $42 \%$ five-year survival in the 1990 s to $56 \%$ more recently. ${ }^{3}$ Although this is an advance forward statistically, from a practical standpoint it is a relatively poor outcome given the labor-intensive efforts of those involved and the costs imposed on the health care industry. The 2 "Achilles' heels" of early primary graft dysfunction and late chronic lung allograft dysfunction (CLAD) remain the major stumbling blocks. No effective preventative measures or treatments have come about despite rather intensive research efforts to solve these mysterious maladies that plague lung transplant recipients.

The article published in this issue of the Journal by the group in Vienna demonstrates a remarkable improvement in the survival in pediatric lung transplantation compared with the registry reports. ${ }^{4}$ In the early era of their experience, the 5-year survival was approximately $50 \%$, similar to the International Society for Heart and Lung Transplantation registry. However, since 2003, this figure improved to a reasonable $75 \%$ (Figure 1). How does one account for this? The authors emphasize the role of retransplantation as therapy for CLAD (a less-insulting

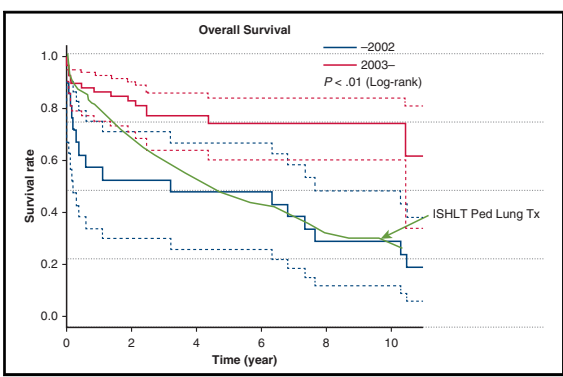

Overlay of International Society for Heart and Lung Transplantation Pediatric Lung Transplant Survival compared with that from Vienna.

Central Message

Medical therapies for primary graft dysfunction and CLAD are ineffective. Aggressive use of ECMO to avoid primary graft dysfunction and retransplantation for CLAD may be the best option to improve pediatric lung transplant survival.

See Article page 2025.

acronym than bronchiolitis obliterans to label those with late lung failure due to fibrotic obliteration of bronchioles) as the main reason for this success. Assuming this is true, does this really represent an advancement in the field of pediatric lung transplantation? If one considers the burden of primary lung transplantation on the battalion of physicians, nurses, therapists, and other allied health care participants, retransplantation is at a higher level altogether with outcomes that are worse than primary transplantation. The cost alone is matter of concern. The hospital costs for primary lung transplant are estimated at $\$ 500,000$ (US); retransplantation is not cheaper. Successful prevention or treatment for CLAD would seem to be a better solution medically and economically.

Although retransplantation is provided as the explanation for the improved results, a closer look at the survival curve suggests something else in my view. The early operative survival is significantly better than in other single-center studies or registry reports. The reasons for this are likely multifactorial and could involve better patient selection (likely), better donor management (possibly), better intraoperative and postoperative care (highly likely), the use of better lung preservative solution (Perfadex, Medisan, Uppsala, Sweden) (probably), or a host of other factors. However, one thing that stands out is the liberal use of extracorporeal membrane oxygenation (ECMO) post-transplant-it was used in 


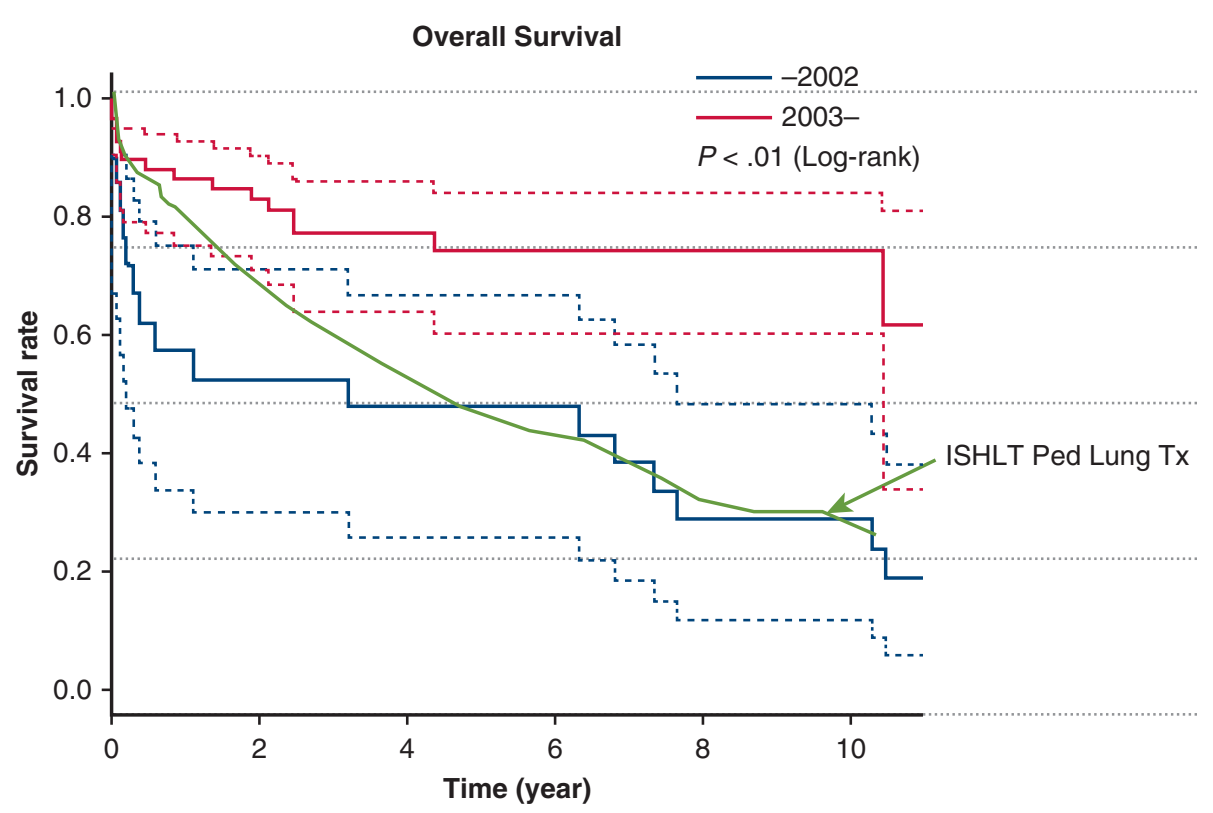

FIGURE 1. The survival curve for pediatric lung transplants performed between 2000 and 2007 taken from the registry of the International Society of Lung and Heart Transplantation is displayed on the survival curve from the article by Waseda and colleagues. ${ }^{4}$ The earlier results from Vienna are similar to a more contemporary survival from the registry. However, the survival curve from transplants performed from 2003 onward diverges in the first year after transplantation and continues to diverge further beyond that. ISHLT, International Society of Lung and Heart Transplantation.

more than one third of all recipients. It is a bit difficult to glean from the literature what the incidence of the use of ECMO post-transplant generally is, but $10 \%$ seems to be a typical figure for most single-center studies. ${ }^{5}$ The indications for ECMO in the Vienna study included increasing ventilator requirements, a high-risk recipient, and a marginal donor. Presumably, respiratory failure with high ventilator settings (and the damaging impact of that) was avoided by preemptively putting the lungs "at rest" during a vulnerable period. ECMO has its own set of risks, of course, including bleeding and infection. There is some evidence that the earlier ECMO is initiated, the quicker the recovery and subsequent decannulation from ECMO. ${ }^{5}$

According to Greek mythology, Achilles himself had only 1 heel vulnerable (the one held by his mother Thetis as she dipped her infant into the River Styx). Unfortunately, lung transplantation has 2-primary graft dysfunction affecting early survival and CLAD affecting late survival.
There are no proven medical treatments for either. The group from Vienna has demonstrated significant improvement in lung transplant survival by surgical approaches for both. Neither actually gets at the root of the problem, but the results speak for themselves.

\section{References}

1. Rossano JW, Cherikh WS, Chambers DC, Goldfarb S, Khush K, Kucheryavaya AY, et al. The registry of the International Society for Heart and Lung Transplantation: twentieth official pediatric heart transplantation report-2017. J Heart Lung Transplant. 2017;36:1060-9.

2. Colvin M, Smith JM, Hadley N, Skeans MA, Carrico R, Uccellini K, et al. OPTN/SRTR 2016 annual data report: heart. Am J Transplant. 2018;18(suppl 1):291-362.

3. Goldfarb SB, Levvey BJ, Cherich WS, Chambers DC, Khush K, Kucheryavaya AY, et al. Registry of the International Society for Heart and Lung Transplantation: twentieth pediatric lung and heart-lung transplantation report-2017. J Heart Lung Transplant. 2017;36:1070-9.

4. Waseda R, Benazzo A, Hoetzenecker K, Jaksch P, Muraközy G, Gruber S, et al. The influence of retransplantation on survival for pediatric lung transplant recipients. J Thorac Cardiovasc Surg. 2018;156:2025-34.

5. Castleberry AW, Martwig MG, Whitson BA. Extracorporeal membrane oxygenation post lung transplantation. Curr Op Organ Transplant. 2013;18:524-30. 